\title{
Reading in the reception classroom
}

Ofated's 2017 review of the Reception year curriculum asserts that reading is the core purpose of the Reception year, and advocates "systematic systematic phonics" as the teaching method. This precept disregards research into the nature of reading in the early years and the professional wisdom of early years teachers.

John Hodgson

Editor, English in Education

\section{Introduction}

Ofsted's (2017) recent review of the reception year curriculum, Bold Beginnings, refers approvingly to the practices of "a sample of good and outstanding primary schools". The review describes the reception year, although not compulsory, as "the start of school". Most parents, it says, decide to send their child to Reception, and, for most schools, it is the start of the national curriculum (p.8). "The basics" - the ability to read, write and use numbers - "need to be taught and learned - well, from the start (p.10)." Reading, moreover, is "at the heart of the curriculum" (p.5). The review recommends (p.7) that all primary schools "should make sure that the teaching of reading, including systematic synthetic phonics, is the core purpose of the Reception Year."

\section{A too simple view of reading}

Nearly half a century after the dawn of post-modern consciousness, this precept suggests a disturbing pursuit of "abstract, theoretical and doctrinaire ideals" (Venturi et al 1972). It is disturbing on two counts. Firstly, every reception class will contain up to 30 or more individuals with heterogeneous purposes and needs. A few may already read silently and with some fluency. To subject either such fully-fledged readers, or those who are well on their way, to a rigid diet of intensive phonics is an affront to their emerging identities as persons (Davis 2013:30). Others may exhibit social or behavioural difficulties that will impede their reading and require attention. Secondly, the teaching of reading, as described in the report, has a highly dubious theoretical basis in that it prioritises one method: "systematic synthetic phonics". This method requires children to "apply phonic knowledge and skills to decode unfamiliar words fluently and accurately, before trying to understand them" (emphasis added) (p.22). In other words, the review apparently endorses the Simple View of Reading (SVR) (Rose 2006), which separates phonic "decoding" from comprehension of meaning. The schools visited, the report asserts, taught children to "apply phonic knowledge and skills as the route to decode words" (emphasis in the original) (p.21). Bold Beginnings (2017) thus echoes the view that has imbued DfE reports on literacy over the last decade: that the key to reading is to learn "grapheme-phoneme correspondences (GPCs)" (p.21). The DfE (2011) report The Importance of Phonics: Securing Confident Reading has an almost messianic fervour, claiming that synthetic phonics is the solution to educational failure and thus to high levels of youth unemployment. Bold Beginnings (Ofsted 2017) is more measured in tone, but conveys the same message:

In the schools that devoted considerable time and resources to letting children practise blending sounds into words, the children made the strongest progress in reading. Focused time during formal teaching, as well as an expectation that phonic books would be read and practised at home, gave children frequent opportunities to develop their fluency so that decoding of the words on the page became automatic - a critical foundation for independent reading. (p.22)

Ofsted (2011) claim that synthetic phonics can enable "the one in six children who were once destined to struggle reading essential text [to] fully participate in their studies and the world of literature" (DfE 2011). If this were indeed the case, Ofsted's (2017) strong emphasis on SSP in the reception year might be justified. However, this simple view fails to understand the nature of reading and the way children learn in the reception class of a primary school. This paper will ex- 


\section{Reading in the reception classroom : page 2}

amine these issues by reference to recent research, including a large-scale survey of early years practitioners conducted by the National Association for the Teaching of English (Hodgson et al 2013).

\section{The rise of synthetic phonics}

In recent years, government in the UK and several other English-speaking countries has promoted the teaching of "synthetic phonics" as the key to success in training young readers. In this approach (sometimes known also as "systematic phonics"), the pupil is supposed to learn the correspondences between sounds (phonemes) and letters: for example, pronouncing each phoneme in shop /sh/-/o/-/p/ and then blending those phonemes to produce the word (DfE 2011). The 2006 Independent Review of the Teaching of Early Reading recommended that synthetic phonics should be taught "discretely" and as the "prime approach" (Rose 2006). As this paper will show, this policy has met detailed and cogent opposition from both researchers and classroom teachers; but the Ofsted (2017) report states that "leaders [in the schools visited] were passionate about the place of systematic synthetic phonics as part of a rich and varied reading programme" (Ofsted 2017: 21). In these schools, we are told, "systematic synthetic phonics played a critical role in teaching [reception year] children the alphabetic code," and reception teachers passed on to year 1 teachers checks of children's phonics knowledge (p.4). "Children read out loud frequently from carefully selected books that closely matched their phonic knowledge" (p.5).

\section{Reading English}

English spelling is governed as much by meaning and word origin as it is by regular "phonemegrapheme correspondences". The quotation marks indicate that the concept of phoneme is debated, but it is not equivalent to letter sounds (Port 2011). Ofsted and the DfE appear confused here, their documents interchangeably using the terms "phonemes" and "letter sounds". Leaving aside this important theoretical distinction, the relationship between letter sounds and their written representations in English is complex and inconsistent. Few if any letters are tied to the "same" sound, and some ("b", "p" and "l") suffer sound death in such words as "lamb", "receipt" and "psalm" (Davis 2013:22). Many common words are heteronyms, where the pronunciation of letter sounds depends on context: "tear", "wind", "row", "lead", "minute", and so on. Despite these common irregularities, synthetic phonics teaches children to "build up" words, through sounding them out, one grapheme at a time. As Dombey (2018) explains: "This works well for languages such as Spanish and Finnish. But it simply does not work for many of the commonest words of English":

Given this complexity, the term 'decoding', when applied to reading English, must be taken to mean more than synthetic phonics. (Dombey 2018)

Children learning to read make use not only of "grapheme-phoneme correspondences" but also of semantic (meaning) and syntactic (grammar) cues from the surrounding text (Goodman et al.2005). Kidd (2013) gives an example of a young reader who had to switch from a phonic to a grammatical approach to decoding:

[Hobie] comes across a word - 'going' - and his phonics knowledge initially tells him that the word is /g/oi/ng/ - like boing ... He hesitates: he has pre-existing knowledge of vocabulary and he self corrects - going. This is not a decoding skill; it is a vocabulary skill. He goes a step further. Writing the word down, he recognises a morphemic pattern - a base and a suffix - and draws a line between the two. This is a whole lot more sophisticated than implementing a decoding skill. Phonics alone would not have got him to the correct pronunciation of the word. 


\section{Reading in the reception classroom : page 3}

One might add that Hobie's pre-existing knowledge of vocabulary has a contextual element: his recognition of the word "going" strongly suggests that he knows what it means.

\section{Teaching (very) young readers}

Davis (2012) argues that the case for synthetic phonics (SP) depends on "fantasies of researchbased teaching". He claims that the case has never been made because a discrete method of teaching synthetic phonics cannot be identified and measured. Studies allegedly showing that intensive discrete SP lessons improve reading achievement in comparison with control groups of similar pupils rarely if ever indicate the exact nature of the lessons concerned (Davis 2013:16). They cannot do so, because no classroom teacher would conform to the narrow method of decoding apparently required; to do so would be to abdicate their role as teachers (Davis (2013:6). Competent teachers will always want pupils to develop "relational understanding", where they can place their new knowledge on an existing cognitive map. For this reason, teachers will naturally view words as units of meaning rather than merely as units for grapheme-phonic decoding. Even if a teacher attempts to implement systematic synthetic phonics as recommended by the DfE, focusing children's attention solely on "phoneme-grapheme correspondences", her professional judgment is likely to inflect the way in which she actually interacts with children, especially in the reception class.

In fact, no DfE, Ofsted, or other reputable report produced during the last decade claims that "systematic, synthetic phonics" alone are sufficient to establish successful early readers. Rose (2006) recommends that synthetic phonics should be taught "discretely" and as the "prime approach"; but this recommendation is preceded by a call for the priority provision of guidance on "developing children's speaking and listening skills"; and it is followed by a further recommendation that:

Phonic work should be set within a broad and rich language curriculum that takes full account of developing the four interdependent strands of language: speaking, listening, reading and writing and enlarging children's stock of words.

Ofsted's (2010) accounts of the phonic methods adopted by 12 exemplary primary schools also acknowledge the importance of complementary strategies. The reported view of one school is that "children do not become fluent readers by using one skill alone". This school, we are informed, supplements phonic instruction by guided reading and "real books" to take home. Another provides boxes of books in every class and uses an unusually long lunch period for individual and guided reading. A third (nursery) school places "great emphasis on story time":

The children enjoy listening to five high-quality books each term from Reception to Year 2: 15 books in the course of a year. Life in the nursery contains a lot of imaginative play, role-play and some practice of phonics.

"Some practice of phonics" is hardly an endorsement of a monocular approach to early reading. The Department for Education's (2011) “evidence paper”, The Importance of Phonics: Securing Confident Reading, itself states: "Phonics teaching must be embedded in a language-rich curriculum". The one UK study regularly cited in favour of synthetic phonics (Johnston and Watson 2005) finds a correlation between children's word reading and spelling in Primary year 7 and the quantity of children's and adults' books available in their home. Bold Beginnings (Ofsted 2017) also acknowledges the importance of a "rich and varied reading programme" (p.21) - but its constant line is that knowledge of phonic "decoding" must precede other kinds of reading (p.22).

\section{Professional views from the classroom: the NATE survey}

Davis (2012:7) has emphasised the importance of professional judgment when teaching reading in the early years. The vast majority of early years teachers, he writes, handle this challenge with professionalism, and will continue to do so if they are not troubled by rigid prescriptions from policy makers. How, then, do teachers actually work with early readers? In 2013, the Na- 


\section{Reading in the reception classroom : page 4}

tional Association for the Teaching of English conducted an on-line survey of teachers' views and practices in relation to the teaching and assessment of early reading (Hodgson et al 2013). The full results of the survey can be found at http://eprints.uwe.ac.uk/35641/.

Of the 445 individuals who completed the survey, more than half taught in infant schools (Hodgson et al, 2013 , p. 4). A majority of these $(203$, or $68.4 \%)$ claimed that phonics was a high priority in their school or department; however, a similar number (200, or $67.3 \%)$ said that their school devoted fewer than five hours a week to the teaching of phonics (p.5). Nearly all infant teachers (272, or $91.6 \%$ ) used a scheme or programme to teach phonics, Letters and Sounds being the most popular scheme (p.6).

No respondent to the survey regarded phonics instruction in early years education as unnecessary, and there was significant support for the view that phonics should be the prime focus of teaching beginning readers (Hodgson et al, 2013, p. 9). Several people agreed with the assertion of the DfE evidence paper (DfE 2011) that the ability to decode "grapheme/phoneme correspondences" is the first requirement for success in reading (Hodgson et al, 2013, p.10). Some respondents who worked with children with special learning difficulties believed that early phonic instruction is particularly important for the progress of such children (p.10). A majority of both infant and junior teachers reported positive effects on their pupils' writing and spelling, and about a third of each group reported positive effects on pupils' comprehension and higher reading skills (p.8). But the view of more than two-thirds of respondents was that, while phonic decoding is an important part of learning to read, other strategies are also vital (p.10). More than a quarter of respondents emphasised the importance of reading for meaning, and there was much concern that an overemphasis on phonics leads to an unbalanced reading curriculum in which other reading skills such as prediction and contextual information are not taken into account. In the view of many, a phonics approach leads to less able children "barking at print" while good readers lose motivation and fail to achieve appropriate assessment results. Some children, it was alleged, develop a style of "reading" that consists merely of phonic decoding. There is less time for reading stories and for listening to young readers, and more time is taken up by "teaching to the test" (the national phonics "check" at the end of year 1). In such classrooms, respondents argue, the overall quality of pupils' literacy experience declines (Hodgson et al, 2013, p.14).

More than a quarter of respondents were concerned that an over-emphasis on phonics teaching and testing failed to take into account the needs and capacities of particular children (Hodgson et al, 2013, p.10). Children for whom English is a second language require an emphasis on textual understanding; phonics approaches fail to provide visual scaffolding to support their learning and these children find it hard to progress under such a regime, which occupies the greater amount of classroom time because of the phonics "check". Many respondents expressed concern that systematic phonics instruction creates more problems for struggling readers, as their cognitive energies are spent trying to sound out words, and they therefore miss the meaning of the text. Several commentators believed that such children need a variety of different strategies in order to progress. Many teachers observed that children of all abilities are less motivated by reading schemes than by real books, as the latter encourage reading for interest and enjoyment (p.14). A teacher of deaf children pointed out (p.11) that her pupils cannot hear phonemes; yet they go on to become fluent readers.

A university researcher took the opportunity (Hodgson et al, 2013, p.15) presented by the survey to set out a summary case against an exclusively phonic approach to early reading:

English is not a phonetically regular language. It does not have a single letter/sound correlation. The teaching of phonics in a systematic way often, therefore, creates more problems for struggling readers. Much of their cognitive energies are spent trying to sound out words, apply phonics rules that are not applicable, and generally misdirect their focus from the true act of reading - constructing meaning. Readers construct meaning from text by employing several cuing systems. When phonics becomes the centre of reading instruction, those other cuing systems are often neglected. Children learn to read by engaging in texts that are read aloud to them, that they can read on their own and with the help of 


\section{Reading in the reception classroom : page 5}

others. Over-complicating the act of reading and reading instruction fails to work. Assessments of phonemic awareness and phonics eat time, misplace instruction, and set fragile readers further behind.

\section{Conclusion}

As professionals in teaching young children to read, assessing their progress, and making strategic interventions where required, many respondents to the NATE survey resented that their judgment and knowledge were not recognised. They were outraged not only by the simple-minded analysis of early reading offered but also by the way in which a limited pedagogical practice has been inscribed in the school curriculum, backed by the authority of the school inspectorate, and made subject to nationally imposed testing. Some pointed out that a single approach to the teaching of reading has commercial advantages for publishers who follow the official line. Many challenged the imposition of an expensive, time-consuming and disruptive "phonics check" on year 1 pupils. Taking a wider view, some respondents pointed out that phonics instruction is not an answer to all social ills, and suggested that those in power see it as a remedy for the deficiencies of other people's children.

As Davis (2013:6) has pointed out, competent teachers of early readers will not impose a rigid and inappropriate reading method on actual children. Reading at any level involves a complex set of skills of which phonic awareness is one important element. The responses to the NATE survey demonstrate that most teachers of reading know this, and reject the specious argument that "systematic synthetic phonics" offers a panacea. Ofsted would gain respect from such teachers if it were to recognise the full nature of meaningful reading in the reception classroom.

\section{References}

Davis, A. (2012) A monstrous regimen of Synthetic Phonics: fantasies of research-based teaching 'methods' versus real teaching. Journal of Philosophy of Education 46 (4), pp.560-573.

Davis, A. (2013) To read or not to read: decoding Synthetic Phonics. Impact 20. London: Philosophy of Education Society of Great Britain.

DfE (2011a) The Importance of Phonics: Securing Confident Reading. London: Department for Education.

Dombey, H. (2018) The Simple View of Reading. https://www.teachingtimes.com/news/thesimple.htm (accessed 5 August 2018)

Goodman, Y.M., Watson, D.J. and Burke, C.L. (2005) Reading Miscue Inventory: From evaluation to instruction. Katonah NY: Richard C. Owen

Hodgson, J., Buttle, H., Conridge, B., Gibbons, D. and Robinson, J. (2013) Phonics and Early Reading: professional views from the classroom. National Association for the Teaching of English. http://eprints.uwe.ac.uk/35641/ (accessed 8 August 2018)

Johnston, R. and Watson, J. (2005) The Effects of Synthetic Phonics Teaching on Reading and Spelling Attainment: a Seven Year Longitudinal Study.

http://www.scotland.gov.uk/library5/education/sptrs.pdf (accessed 3 January 2016).

Kidd, D. (2013) Phlipping Phonics. Love Learning. http://bit.ly/H1y74P (accessed 15 October 2013).

Ofsted (2010) Reading by six: how the best schools do it. London: Office for Standards in Education.

Ofsted (2017) Bold Beginnings: the reception curriculum in a sample of good and outstanding primary schools. https://www.gov.uk/government/publications/reception-curriculum-in-goodand-outstanding-primary-schools-bold-beginnings (accessed 6 August 2018)

Port, Robert F. (2011) Phones and phonemes are conceptual blends, not cognitive letters. Accepted for presentation at the Cognitive Science Soc. Annual Meeting, July, 2011, Boston. Rose, J. (2006) Independent Review of the Teaching of Early Reading: Final Report. London: Department for Education.

Venturi, R., Scott Brown, D. \& Izenour, S. (1972) Learning from Las Vegas. Cambridge, Mass.: MIT Press. 